\title{
ЭМОЦИОНАЛЬНЫЙ ИНТЕЛЛЕКТ И ПРАВО: СВЯЗЬ, ПРОБЛЕМЫ, ПЕРСПЕКТИВЫ ИССЛЕДОВАНИЙ ${ }^{1}$
}

В последнее время в юридической науке возникли новые исследовательские сферы, которые пытаются осмыслить правовые явления под новым углом, отказываясь от использования научного фокуса традиционных правовых школ, как, например, чистого правоведения Ганса Кельзена или социологической школы права, но ставя на пьедестал исследований личность как главного носителя права. Человеческое измерение права может проявлять себя не только через призму общества и поведения в нем человека, но и в индивидуальнопсихологическом плане. Западная философско-правовая наука уже имеет в своих рядах исследователей, которые начали изучать взаимосвязь права не только с рациональным началом человеческого ума, но и с более древними и глубинными психологическими сферами. В отечественном научном пространстве мы можем встретить статью-обозрение С. Максимова «Право, разум и эмоции: Всемирный конгресс по философии права и социальной философии», которая посвящена краткому изложению главных и наиболее интересных докладов этого научного мероприятия. Также стоит обратить внимание на перевод статьи Р. Вест «Правовые эмоции». Большинство исследователей отказываются от превалирования рациональной презумпции при понимании

${ }^{1}$ Робота переможця П'ятого всеукраїнського конкурсу наукових робіт «Людський вимір права», присвяченого вшануванню пам'яті Марка Пилиповича Орзіха. права, они пытаются найти его корни и истоки (как пишет Сергей Максимов «конституционные процессы, по его мнению (Андраша Шайо), являются результатом эмоционально нагруженных познавательных процессов» [6]), связи права с отдельными эмоциями, как это делает Р. Вест в «Правовых эмоциях». Отдельные зарубежные публикации подчеркивают важность обучения эмоциональному интеллекту будущих правоведов, например, как это делает Сильвер Марджори в работе «Эмоциональный интеллект и юридическое образование» [3]. Стоит отметить наличие первых практических пособий по развитию эмоционального интеллекта для юристов, например, издания в 2018 году Американской ассоциацией адвокатов книги Ронды Мьюир «За пределами умного: занятия правом с эмоциональным интеллектом». Существуют и профессиональные публикации, например, «Почему уголовные защитники должны беспокоиться об эмоциональном интеллекте?» в журнале «Для защиты» [9].

В нашем исследовании мы попробуем предложить отличный от указанных выше авторов фокус исследования: каким образом связан эмоциональный интеллект, а не просто отдельные эмоции с правом, насколько "law in action" в деятельности отдельного человека зависит от развитого эмоционального интеллекта, каким образом эмоциональный интеллект может влиять на общественно-правовые процессы, в том числе укрепление верховенства

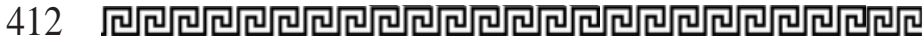


права и конституционной демократии. В самом конце мы попробуем предложить рамки исследовательского поля для будущих исследований и рекомендации общественно-политическим институтам. Изыскание может быть полезным и для обогащения теории правового влияния на личность, которую разрабатывал М.П. Орзих, так как позволяет углубить понимание психологических факторов при реализации правовой программы личностью [5].

Бурное развитие теорий эмоционального интеллекта берет свое начало от издания в 1983 году книги Говарда Гарднера «Структура мышления», в которой он обосновывает успех в жизни не только монолитным интеллектом, но и широким спектром из 7 ключевых способностей. Среди них можно выделить способности к выявлению, дифференциации, наименованию собственных и чужих эмоций, использованию эмоциональных навыков для управления процессами мышления и поведения согласно потребностям организма или окружающей среды, достижению поставленных личностью целей [1]. Совокупность этих качеств определяют как эмоциональный интеллект, в зависимости от их развитости к выявлению, наименованию, контролю эмоций и т. д. можно выделить высокоразвитый и низко развитый эмоциональный интеллект.

Развитый эмоциональный интеллект является одной из важнейших предпосылок к превращению теоретических предписаний права, нормативной программы в "law in action" (право в действии). Его развитие у некоторой части граждан является необходимым для нормального функционирования системы права и общества, но желательным является как можно более высокий уровень его развития у как можно большего количества граждан.

Каждый правопорядок может реализовываться либо на основании личного и свободного поддерживаю- щего его индивида и в совокупности общества, либо же на государственном насилии, но государственно-правовое насилие имеет свой потолок, а именно возможную меру применения публичного, легитимного насилия к наибольшему числу непокорных такому порядку с целью заставить их исполнять установленные нормы. Очевидно, что количество тех, к кому можно применить насилие с целью выполнения предписаний, будет меньше общего количества субъектов права, которых эти предписания касаются. Соответственно, более важным для эффективного функционирования права в обществе является его горизонтальное восприятие и легитимация, нежели вертикальная, формальная и только видимая покорность. Вертикальная подчиненность праву не делает правовой порядок родным гражданам, он не считается ими чем-то важным, но часто воспринимается ограничением, которое наброшено на шею свободного индивида. М.Ф. Орзих считал подобный процесс «системой форм и методов передачи личности социально-правовой программы и восприятия, переработкой ею (личностью) этой программы, проявлением этой программы в правовой деятельности личности» [5].

В ситуациях личной и общественной жизни развитый эмоциональный интеллект позволяет человеку поступать не по первому призыву нервной системы, реакции которой сформировались в далеком прошлом и не всегда соответствуют реалиям сегодняшнего дня, а чувствовать и обозначать возникшие эмоциональные состояния и при необходимости постараться передать возможность принять решение рациональной части мозга. Правовое чувство и ощущение справедливости, «что основывается на совести индивида, не исчерпываются первым, подсознательным чувством, они доступны - хоть и ограничено - контролю со стороны разума и «рационализации»» [8]. Попытки 
распознать подсознательные чувства и понять причину, суть их зависят во многом от эмоционального интеллекта, а это позволяет затем принимать более взвешенные решения.

В связях между эмоциональным интеллектом и правом можно выделить две такие группы связей: позитивно-перспективные, в которых эмоциональный интеллект позволяет достигать неких целей; негативные, то есть воздержание от действий и реакций, которые были необходимы в естественном, первобытном состоянии, но не являются настолько же полезными сейчас и иногда становятся вредными в условиях цивилизации и современного общества.

Развитый эмоциональный интеллект позволяет лучше распознавать и отличать свои и чужие эмоции, причины их возникновения и потенциальные действия, которые могут быть сделаны под воздействием психологических состояний. Такие способности позволяют избежать чрезмерного возбуждения нервной системы, которое может привести к потере контроля над собой и совершению противоправных или общественно-нежелательных действий. Распознание эмоционального состояния другого в соединении со способностями межличностного общения дает возможность повлиять на него и избежать совершения им противоправных действий. В информационном поле мы часто можем встретить примеры влияния эмоционального состояния на поведение личности: «не помня себя от гнева, убил парня» [10]. Эмоциональный интеллект играет важную роль не только в уголовном праве, но и в трудовых, образовательных, конституционно-административных и других правоотношениях. Мы можем наблюдать, как низкий уровень эмоционального интеллекта часто приводит к дракам и публичным конфликтам между представителями государства, что мешает им сотрудничать и исполнять свои обязанности. Достаточно известными являются выплескивание стакана с водой министром МВД Украины на губернатора Одесской области, частые потасовки между депутатами Верховной Рады и других органов государственной власти. Проблема не замкнута на национальном уровне: подобные вещи происходят во многих парламентах, например, Турции, Таиланда, Италии. По информации многих медиа и экспертов, Президент и Премьер-министр «Ющенко и Тимошенко больше воевали между собой» [11], что находило такое выражение во влиянии на право и правоотношения:

- приостановление действия актов Кабинета Министров Украины Президентом Украины, хотя мы и не можем быть полностью уверенными в отсутствии правовых оснований для такого;

- ослабление доверия к наивысшим актерам национальных правоотношений, что приводило к ослаблению доверия к принятыми ими нормативно-правовым актам и государственно-правовым институтам в целом.

Следует отметить порой низкий уровень эмоционального интеллекта среди профессиональных юристов или уполномоченных государством лиц на применение насилия, что находит свое выражение в ненадлежащем исполнении своих обязанностей. $\mathrm{K}$ примеру, известен случай, когда полицейский в ярости застрелил 10 людей [16]. Многие адвокаты во время рассмотрения дела переходят от рассмотрения правовых позиций другой стороны и обоснования своей к "argumentum ad personam": «Большое количество адвокатов в своих судовых речах обругивают прокурора» [13]. Иногда судебные заседания превращаются в настоящие драмы, которые не оставляют равнодушными многих участников процесса, но эмоциональные реакции не помогают решить дело согласно верховенству права и установить справедливые правовые последствия, а также создают множество других 
проблем. Подобные явления могут быть связанны как с низким уровнем образования некоторых юристов, так и с проблемами самоконтроля, непониманием эмоциональных состояний и неспособностью успокоить других участников процесса.

Эмоциональный интеллект имеет большое значение для функционирования демократических институтов. Его низкий уровень часто имеет последствием социальную эксклюзию человека, что исключает поддержку многих социальных связей и установление новых. Это приводит к абсенции человека в публичном пространстве или трудностям адаптации и коммуникации в таковом, что усложняет делиберативные возможности демократии и не содействует общей конструктивной разработке и принятию решений.

Низкий эмоциональный интеллект часто связан с пессимистической интерпретаций жизненных событий и возможным чувством беспомощности. Личности, которые имеют конфликты и могут их решить в правовой форме, часто не имеют доверия к праву и не надеются изменить ситуацию, отстоять свои интересы («мы не ходили туда, нам же матюков нагнут там, вы же знаете» [15]). Это может вести к полному отказу использовать юридические средства даже там, где совершаются опасные общественные правонарушения. Другой стороной этого явления являются самоубийства, которые хоть и не считаются нарушением закона, но имеют негативную социальную природу.

Развитый эмоциональный интеллект позволяет «принимать сбалансированное в эмоциональном плане решение, сначала контролируя импульс к действию, затем определять альтернативные действия и их последствия до того, как поступить тем или иным способом», «чувства являются неотъемлемой частью принятия рациональных решений они ориентируют нас в правильном направлении, а там в игру вступает логика» [2], что позволяет принимать рациональные и взвешенные правовые решения. Эмоциональный интеллект включает чувство ответственности за поступки и обещания, стимулирует к взвешиванию положительных и отрицательных сторон правовых и других решений. Подобное поведение налаживает отношения между людьми, повышает эффективность общения, приводит к возрастанию доверия между людьми и представляемыми ими институциями. K слову, доверие между членами общества, избранными ими представителями и институциями является одним из маркеров эффективных демократических и конституционных строев. Вероятно, граждане с более развитым эмоциональным интеллектом лучше понимают меры допустимого поведения и более ответственно используют свои правовые возможности.

Не стоит забывать о легитимности принятых публичной властью решений, в том числе судебных, что часто зависит от «человечности» самого решения или же «человечного» его объяснения. При принятии правовых предписаний уполномоченные публичные лица, как мы убеждены, должны не только апеллировать к рациональным аргументам и основаниям, но и добавлять K ним «человеческое обоснование». В теории права есть исследователи, которые отдельно выделяют «Соломонов метод» с «выраженным чувством справедливости, для которого правосудие требует практического разума, а значит, не может осуществляться без эмпатии, сопереживания» («Гнев разума и благодать чувств: оправдывая чувства в праве», П. Миндус) [6]. Продолжая тему взаимодействия права и внедряющих его в жизнь институтов, отмечаем пользу для эффективности государственного аппарата его как можно большей «человечности» не только в контексте аргументации решения, но и касательно самой правовой процедуры, которая должна стремиться 
к уменьшению негативных эмоций во время обращения к ней человека и по мере возможности создания положительных.

В юридической практике эмоциональный интеллект составляет важную часть общения между юристом и клиентом. Клиенты юристов нуждаются в комфортном общении, понимании своих потребностей, вовлеченности в решение правовой проблемы. Юристы во время судебных процессов могут использовать эмоциональные навыки для коммуникации с другими участниками процесса, к примеру, привлекать в процесс свидетелей или другие стороны, которые не планировали принимать в нем участие.

Эмоциональный интеллект не только имеет значение в контексте превращения правовых предписаний в реальное поведение субъектов и надлежащего восприятия ими норм права, но и может стать частью определенных правовых институтов.

В сфере уголовно-правовой политики государства учет оценки эмоционального интеллекта человека может найти свое место в Уголовном кодексе как основание смягчения уголовной ответственности, возможно, с оговоркой, что только в случаях неумышленных преступлений. Результаты оценки эмоционального интеллекта могут быть одним из оснований позитивного или негативного решения уполномоченными лицами вопроса о досрочном освобождении лица от отбывания наказания во время амнистии или помилования. Считаем необходимой разработку специальных курсов повышения уровня эмоционального интеллекта для лиц, которые отбывают наказание, связанное с ограничением свободы с целью действительного, а не только декларированного в УК исправления осужденных, а также предотвращения новых уголовных правонарушений. Подобные учебные программы можно сделать обязательными для лиц, которые совершают менее тяжкие правонарушения, особенно тех, что были совершены вследствие потери человеком самообладания.

В гражданском праве результаты оценки эмоционального интеллекта могут быть положены в основу предоставления полной гражданской дееспособности лицам, к примеру, в рамках украинского права с 16 лет.

В трудовом праве оценка эмоционального интеллекта может найти место во время принятия лиц на работу, если обязанности связаны с частым и интенсивным общением с другими людьми, в том числе в среде, где высок уровень риска появления конфликтов.

В конце стоит определить дальнейшие пути развития изучаемой проблематики. В сфере права и психологии с учетом положений этой работы стоит попробовать эмпирично исследовать уровень развития эмоционального интеллекта среди украинских граждан, обращая внимание на другие социально-психологические характеристики, а также попробовать установить корреляцию между ними. В глобальном измерении можно предпринять исследование многих обществ, мы можем предполагать, что разные социумы имеют разный уровень эмоционального интеллекта, что обусловлено экономическими, правовыми, социальными, культурными и образовательными условиями, индивидуальными психологическими особенностями членов общества. Кажется интересной и менее масштабная идея обследования профессиональной правовой среды, а именно адвокатов, представителей органов правопорядка, сравнение результатов с показателями их успешности в позитивном (количество выигранных дел или удовлетворенность клиентов их работой, склонность рекомендовать их другим), так и в негативном (количество привлечений к ответственности) аспектах. В сфере практики следует создать специальные учебные курсы по повышению уровня эмоционального интеллекта для личностей, 
которые имели проблемы с законом, предложить студентам-юристам учебные курсы по эмоциональному интеллекту по выбору, как это сделано в некоторых зарубежных университетах. Мы убеждены, что обучение эмоциональному интеллекту, даже несмотря на некоторые угрозы, которое оно может нести при недостаточно профессиональной разработке учебной программы, является предпосылкой к улучшению правоотношений и уменьшению девиантных явлений в социальной жизни, в частности в "law in action". Подобные меры будут содействовать развитию ответственности на горизонтальном уровне за национальную программу деятельности и восприятие ее личностями в качестве индивидуальной, дальнейшему укреплению верховенства права и модернизации Украины.

У статті розглянуто понятmя, особливості, роль та вплив емоиійного інтелекту в різних проявах права та правовідносин. Визначено, що емоційний інтелект полягає у здатності людини виявляти, розуміти та контролювати емоційні стани себе та інших, використанні навичок емоціиного інтелекту для досягнення поставлених изілей. Автор обтрунтовує важливість емоційного інтелекту та сприйняття права індивідом, наводить позитивні та негативні приклади впливу емоційного інтелекту на право. Зокрема, особливий акиент робиться на сфері публічного права: вплив нерозвинутого емоиійного інтелекту на скоєння особою правопорушень, здійснення обов'язків представниками держави, зокрема найвищими акторами правового поля та правниками. Наголошується на важливості розвинутого емоційного інтелекту для функціонування демократичного врядування, особливо для реалізаціі деліберативного потениіалу народовладдя. Увагу приділено важли- вості «людського» обтрунтування права як передумови його виконання та сприйняття правових приписів як дійсної програми у діяльності особистості. Надалі пропонуються перспективні шляхи імплементаизї оцінки емоційного інтелекту в різні галузі права, зокрема кримінального, ичвільного, трудового. Наприклад, пропонується враховувати емоиійнй інтелект під час звільнення особи від відбування покарання, пом'якшення покарання, організащії спеціальних курсів для правопорушників. Наприкінuі автор пропонуе теоретичні та практичні шляхи розвитку досліджуваної проблематики, наполягає на необхідності створення спеціальних вибіркових навчальних курсів з підвищення емоційного інтелекту для правників. Автор подає думку про організацію емпіричного дослідження емоційного інтелекту серед правничої спільноти задля встановлення кореляиіі мін рівнем розвитку емоційного інтелекту та професійного успіху правника.

Ключові слова: емоційний інтелект, право, правосвідомість, теорія правового впливу на особистість.

Andreiev T. The emotional intelligence and law: problems and perspectives

The research is aimed to explore the role, impact and importance of emotional intelligence in the law and concerned social relations. The article defines emotional intelligence as an ability of people to recognize, name, control and understand their own emotions and the emotional condition of other people, using emotional skills to achieve some goals. This research paper argues that a high level of emotional intelligence in each member of the legal relationship is important for the law in order to become the law in action. The study gives some examples of positive and negative impact of emotional intelligence on law. The accent is made on public sphere of 
law, especially in criminal and constitutional relationships, for example the role and impact of low-level emotional intelligence on the commitment of crimes, execution of public duties by representatives of the government etc. The attention is also paid to the importance of emotional intelligence on democracy and the impact on the deliberative possibilities of democracy. This work outlines the possible future implementation of the evaluation of emotional intelligence in legal order, for example in criminal, civil, labour law. The evaluation of emotional intelligence can be used in sentencing, remission from the punishment during the amnesty or oblivion, the author proposes to organize special courses that are aimed to raise the emotional intelligence of the perpetrators. In the end the author describes the ways of future development of the researched question, gives some ideas about empirical researches of the level of emotional intelligence among lawyers in order to find correlation between the level of emotional intelligence and the professional success. Also, there is a proposal to create special educational courses for the students in law in Ukraine that will help them to improve their emotional intelligence and subsequently can lead to better communication between people and lawyers.

Key words: emotional intelligence, law, sense of justice, the theory of the legal impact on people.

\section{Литература}

1. Colman A. A Dictionary of Psychology. 2008.

2. Гоулман Д. Емоційний інтелект / пер. з англ. С. Гумецької. Харків : Віват, 2019. 512 c.

3. Silver M.A. Emotional intelligence and legal education. Psychology, Public Policy, and Law. 1999. № 5.

4. Stannard J., Heather C. Becoming Like Solomon: Towards an Emotionally Intelligent Legal System. The Emotional Dynamics of Law and Legal Discourse. 2016.

5. Орзих М.Ф. Избранные труды: юбилейное издание к 90-летию со дня рож- дения / сост. А.Р. Крусян, А.А. Езеров ; вступ. ст. С.В. Кивалов. Одесса : Юридическая литература, 2015. $568 \mathrm{c}$.

6. Максимов С.И. Право, разум и эмоuзии: XXVII Всемирньй конгресс по философии права и социальной философии. Правоведение. 2015. № 6. С. 211-219.

7. Вест Р. Правові емоції. Філософія права і загальна теорія права (українська мова). 2015. № 1.

8. Райнгольд Ц. Філософія права. Київ : Тандем, 2000. 300 c.

9. Ronda M. Why criminal defense lawyer should care about emotional intelligence. PACDL: Pennsylvania Association of Criminal Defense Lawyers. 2019. № 4.

10.На Херсонщині чоловік убив кохания своєї цивільної дружини $і$ поховав його в кориті. Інформаційне агенство «Унiaн». 2019. URL: https:// wrw.unian. ua/incidents / 10732314-na-hersonshchinicholovik-ubiv-kohancya-svoyeji-civilnojidruzhini-i-pohovav-yogo-v-koriti.html (дата звернення: 10.12.2020).

11. Лосєв I.В. Віктор Ющенко: итрихидо політичного портрету. Українська правда. 2010. URL: https: / / www.pravda.com.ua/ columns / 2010/07/23/5239655 (дата звернення: 10.12.2020).

12. Ющенко зупинив дію низки постанов Тимошенко. Ліга. Новини. 2009. URL: https: / / ua-news.liga.net / economics / news / yushchenko-zupiniv-d-yu-nizkipostanov-timoshenko (дата звернення 10.12.2020).

13. Захист на публіку (інтервю з адвокатом Генріхом Падвою). Закон $i$ бізнес. 2020. URL: https://zib.com.ua/ ua / 144777-advokat_genrih_padva_duzhe_ malo_hto_virit_u_chesnu_sumlinnu_html (дата звернення: 10.12.2020).

14. Москалюк О.М. Чомув українському парламенті б’ються? Українська правда. 2015. URL: https: / / www.pravda.com.ua/ columns/2015/03/11/7061075 (Jama звернення: 10.12.2020).

15. Чи знають лозівчани права покупия? Лозівська панорама (ТРК Лозова). URL: http://lozovarada. gov.ua/televizijni-novini/chy-znaiutlozivchany-prava-pokuptsia.html (Jama звернення: 10.12.2020).

16. Полищейский в приступе ярости застрелил 10 человек в Кении. PИА Новости. 2010. URL: https://ria. ru/20101107/293455663.html (Dama звернення: 10.12.2020). 